\title{
Modificational Changes in Function and Morphology of Cultured Macrophages by Geraniin
}

\author{
Yumiko Ushio, Tang Fang, Takuo Okuda ${ }^{1}$ and Hiroko Abe \\ The Research Institute of Orientat Medicine, Kinki University, \\ 377-2 Ohno-higashi, Osaka-sayama, Osaka 589, Japan \\ 'Department of Pharmacognosy, Faculty of Pharmaceutical Sciences, Okayama University, \\ Tsushima, Okayama 700, Japan
}

Received March 18, 1991 Accepted July 1, 1991

\begin{abstract}
Treatment of peritoncal macrophages with geraniin, isolated from Geranium funbergii, markedly induced the phagocytosis of living yeasts. Marked increases in phagocytosis and acid phosphatase activity in macrophage lysates were observed $24 \mathrm{hr}$ after the beginning of geraniin treatment. As observed by electron microscopy, macrophages that had been treated for $24 \mathrm{hr}$ with geraniin had a markedly thickened surface layer which was positive to ruthenium red, compared to the control cells. In addition, geraniin treatment of macrophages appeared to induce remarkably large mitochondria, more coated pits and prominent lysosomal granules. In conclusion, the stimulation of phagocytosis and acid phosphatase activity of macrophages by geraniin treatment may involve alterations of the plasma membrane and cytoplasmic reorganization.
\end{abstract}

Geraniin, isolated from Geranium funbergii, belongs to a group of related tannins that have been reported to show many pharmacological activities such as inhibition of histamine release from mast cells (1), the ability to affect some platelet functions $(2,3)$, the lymphoproliferative effect (4) and the immunomodulatory effect (5), based upon binding tannins to membrane surface proteins of each cell (6). Recently, it has demonstrated that tannin mediates some functions of macrophages (7, 8). We have also reported that geraniin treatment in vitro induces significantly increased spreading of cultured macrophages and related changes in cytoskeletal organization (Y. Ushio ct al., unpublished data). To further explore these issues, we examincd the effects of geraniin on the phagocytosis, yeast killing activity and acid phosphatase activity in mouse peritoneal macrophages. We also reported that the modificational changes of functional activities by geraniin treatment might be caused by the altered plasma membrane and cytoplasmic reorganization.

\section{MATERIALS AND METHODS}

\section{Animals}

Macrophages werc collected from male mice of the BALB/C strain (b.w. 25-30g) obtained at the Shizuoka Experimental Animal Lab.

\section{Cell culture}

The mouse peritoneal macrophages were harvested by intraperitoneal injection to mice with Eagle's minimum essential modium (MEM: Nissui). The peritoneal cells were obtained by centrifugation at $1,200 \mathrm{rpm}$ at $4^{\circ} \mathrm{C}$ for $10 \mathrm{~min}$ and were gently resuspended in MEM medium supplemented with $10 \%$ fetal 
calf scrum (FCS). The cells were plated on culture dishes (Falcon: $35 \times 10 \mathrm{~mm}$ ) at a concentration of $5 \times 10^{4}$ cells/dish and were incubated at $37^{\circ} \mathrm{C}$ in a $5 \% \mathrm{CO}_{2}$ atmosphere for 2 hr. Nonadherent cells were then gently removed by washing with Hank's balanced salt solution (HBSS), and the adherent cells were incubated in $10 \%$ FCS-MEM medium for 24 hr.

\section{Addition of geraniin}

After the macrophages were incubated for $24 \mathrm{hr}$, the cells were washed, and geraniin (Fig. 1) was added to the cell cultures with $2 \%$ FCS-MEM medium at the final concentrations of $2,5,10$ and $20 \mu \mathrm{g} / \mathrm{ml}$. Geraniin used for the experiments was dissolved in ethanol (final concentrations of ethanol in the medium were $0.1 \%$ ). The cells were further incubated for $1,4,8,24$ and $48 \mathrm{hr}$ at $37^{\circ} \mathrm{C}$ in a $5 \% \mathrm{CO}_{2}$ atmosphere.

\section{Phagocytosis of living yeasts}

Phagocytosis was examined at $1,4,8,24$ and $48 \mathrm{hr}$ after addition of geraniin. The living yeasts used for the experiments were from stock cultures of Saccharomyces cerevisiae (7$8 \mu \mathrm{m})$ maintained at $30^{\circ} \mathrm{C}$ on Sabouraud's dextrose agar slants. The yeasts were added with $10 \%$ FCS-MEM medium suspension into the macrophage cultures at a concentration of 100 yeasts/single macrophage. The cells were incubated with yeasts at $37^{\circ} \mathrm{C}$ for $15 \mathrm{~min}$ in a $5 \% \mathrm{CO}_{2}$ atmosphere, washed thoroughly with phosphate-buffered saline (PBS) and fixed with $1 \%$ glutaraldehyde in PBS for $5 \mathrm{~min}$. The number of yeasts ingested by a single macrophage was evaluated for 200 macrophages in random fields under phase contrast microscopy, and the values were expressed as the mean \pm standard error. Furthermore, by electron microscopical observation, we confirmed the intracellular ingestion of yeasts by geraniin $(20 \mu \mathrm{g} / \mathrm{ml})$-treated macrophages instead of simple attachment of yeasts to the cells (Fig. 2).

\section{Intracellular killing of living yeasts}

We examined intracellular killing activity of living yeasts by macrophages according to the method described by Grasso and Guay (9) After the phagocytosis assay made by 15 minincubation of the control and geraniin-treated macrophages with yeasts, extracellular yeasts were thoroughly removed, and one series of control and geraniin-treated macrophages were immediately exposed for $30 \mathrm{~min}$ to distilled water at room temperature. Liberated yeasts were diluted in PBS, plated on Sabouraud's dextrose agar plates, and then the

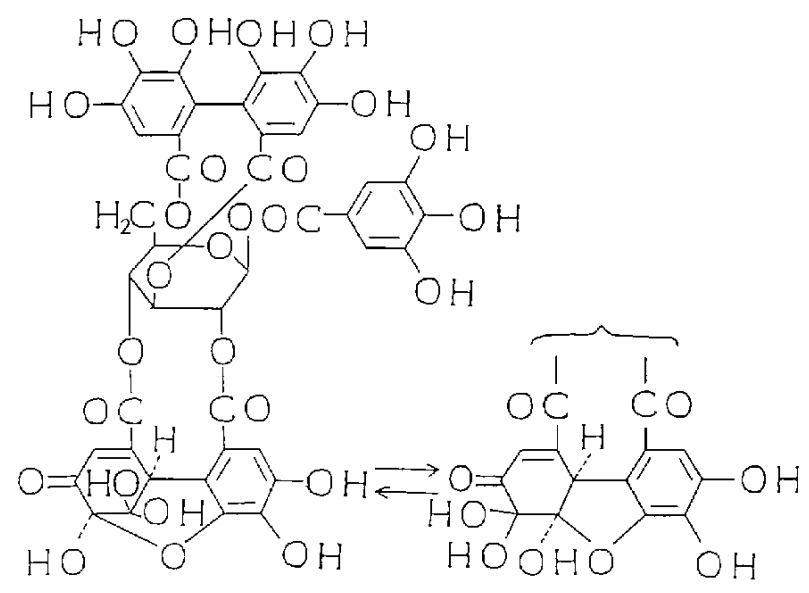

Fig. 1. The chemical structure of geraniin. 


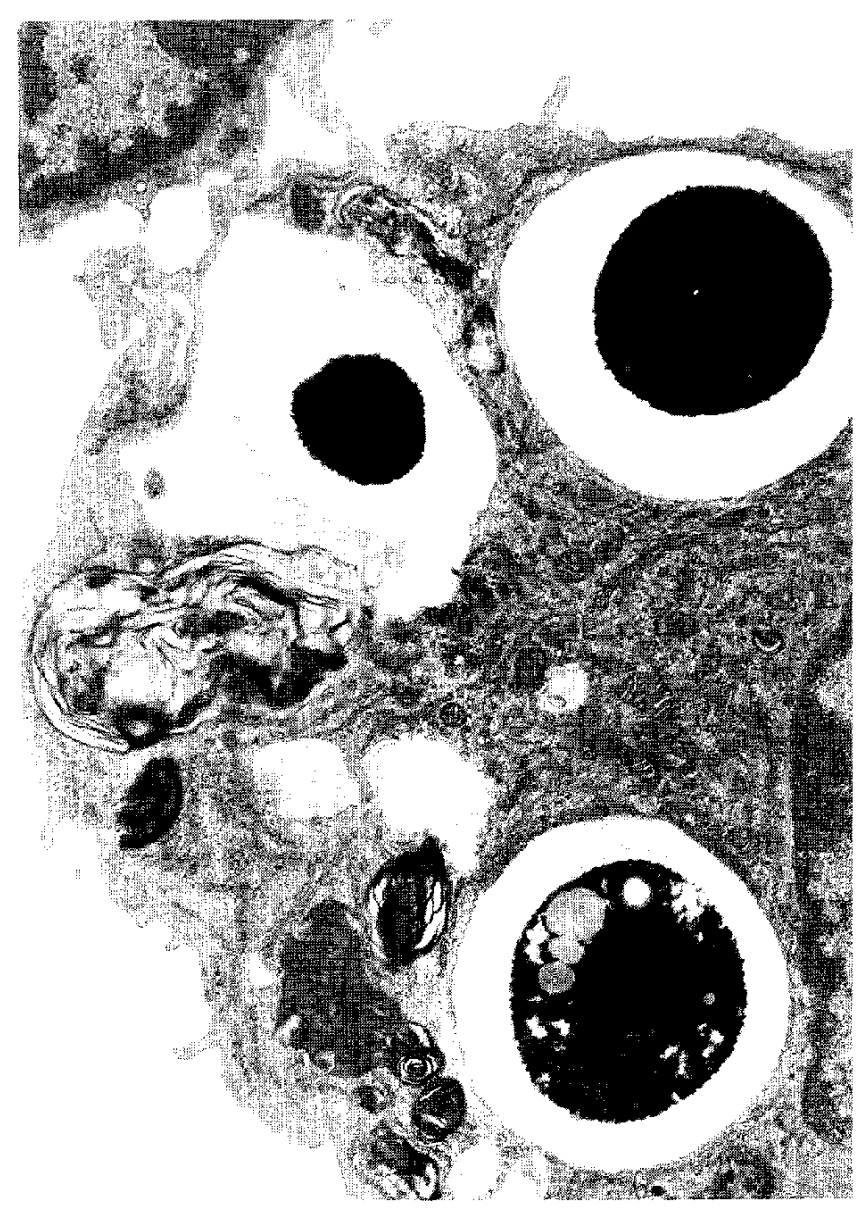

Fig. 2. Transmission electron micrograph of macrophages treated with geraniin $(20 \mu \mathrm{g} / \mathrm{ml})$ for $24 \mathrm{hr}$ and then incubated with yeasts for $15 \mathrm{~min}(\times 20,000)$.

agar plates were further incubated at $30^{\circ} \mathrm{C}$ for $48 \mathrm{hr}$. The other series of control and geraniin-treated macrophages were incubated with yeast-free fresh $10 \%$ FCS-MEM medium for an additional $165 \mathrm{~min}$ and $345 \mathrm{~min}$ and were then also lysed with distilled water. The yeasts liberated from the macrophages were plated. The colonies of yeasts on the agar plates were counted, and the total numbers of viable organisms per macrophage culture dishes were calculated.

\section{Acid phosphatase activity}

The macrophages $\left(1 \times 10^{5}\right.$ cells $/$ dish $)$ in cul- ture dishes were solubilized by incubating for 30 min with $0.1 \%$ Triton $X-100$ in distilled water. Acid phosphatase activity in the lysates of the cells was determined by a using kit (Acid phosphatase kit, Wako). Protein concentration of the lysates was estimated by dyc reagent (Bio-Rad) using bovine serum albumin as a standard.

\section{Transmission electron microscopy}

The cells incubated with $2 \%$ FCS-MEM medium containing geraniin for $24 \mathrm{hr}$ were washed with HBSS and fixed with $1 \%$ glutaraldehyde at room temperature for $1 \mathrm{hr}$. After 
a brief rinse with PBS, the cells were postfixed for $1 \mathrm{hr}$ with $1 \%$ osmium tetroxide $\left(\mathrm{OsO}_{4}\right)$ in PBS, stained in $3 \%$ uranyl acetate for $30 \mathrm{~min}$ and washed with distilled water. The cells were dehydrated through a graded series of ethanol concentrations and cmbedded in Epon 812 at room temperature for $1 \mathrm{hr}$. The embedded block was removed from the culture dishes and trimmed. The ultra thin sections were made on an ultramicrotome, stained in $3 \%$ uranyl acetate, lead citrate and examined by a Hitachi HS-9 electron microscope.

\section{Labelling with ruthenium red staining}

The cells incubated with $2 \%$ FCS-MEM medium containing geraniin for $24 \mathrm{hr}$ were fixed with $1 \%$ glutaraldehyde in $0.2 \mathrm{M}$ veronal buffer containing $0.5 \mathrm{mg} / \mathrm{ml}$ of ruthenium red at room temperature for $1 \mathrm{hr}$ and postfixed for $1 \mathrm{hr}$ with $1 \% \mathrm{OsO}_{4}$ in the same buffer which also contained $0.5 \mathrm{mg} / \mathrm{ml}$ of ruthenium red. The following process was the same procedure as the above method of transmission electron microscopy.

\section{Morphometry}

The areas of cytoplasmic mitochondria within macrophages were determined using an electronic planimeter (Numonics) on electron micrographs of the cells fixed $24 \mathrm{hr}$ after the addition of geraniin $(20 \mu \mathrm{g} / \mathrm{ml})$. The mean area of all mitochondria seen within 10 cells chosen randomly from the control and geraniin-treated groups was expressed as mean $\mu \mathrm{m}^{2} \pm$ standard error. For measurement of the mitochondrial areas, electron micrographs were taken at a magnification of 12,000.

The thickness of the ruthenium red-positive layer on the surface membranc of macrophages was also calculated using a micrometer on electron micrographs of the cells fixed $24 \mathrm{hr}$ after addition of geraniin $(20 \mu \mathrm{g} / \mathrm{ml})$. The width of the layers at several points, about $1.7-\mu \mathrm{m}$ apart, was calculated per single macrophage. The mean thickness of 10 cclls randomly chosen from the control and geraniin-treated groups was expressed as the mean $\mathrm{nm} \pm \mathrm{S}$.E. For measurements of the thickness of the ruthenium red-positive layer, electron micrographs were taken at a magnification of 40,000 .

\section{Statistical analysis}

All values represent the mean and standard error of threc separate experiments. Statistical analysis was performed by Student's $t$-test for unpaired observations.

\section{RESULTS}

\section{Effect of geraniin on phagocytosis of yeasts}

The effect of geraniin on phagocytosis of yeasts was determined at $1,4,8,24$ and $48 \mathrm{hr}$ after addition of geraniin to macrophages. The macrophages treated with geraniin showed increased phagocytosis of ycasts from $8 \mathrm{hr}$ after addition. The increases in phagocytosis were $19 \%, 39 \%$ and $37 \%$, respectively, at 8,24 and $48 \mathrm{hr}$ after the addition of geraniin (10 $\mu \mathrm{g} / \mathrm{ml})$, in comparison to the control cells (Table 1).

\section{Effect of geraniin on acid phosphatase activity}

Acid phosphatase activity of macrophages at $1,4,8,24$ and $48 \mathrm{hr}$ after addition of geraniin was examined. The enzyme activity of control macrophages was maintained at the same level for the first $24 \mathrm{hr}$ after the change of the medium to $2 \%$ FCS-MEM medium. However, the level of enzyme activity fell at $48 \mathrm{hr}$ after changing the medium. The geraniin-treated macrophages showed the same level of enzyme activity as the control cells at 1, 4 and 8 hr after the addition of geraniin. The enzyme activity significantly increased in geraniin-treated cells at $24 \mathrm{hr}$ after the addition. The activities of the cells treated with geraniin at concentrations of 10 and $20 \mu \mathrm{g} / \mathrm{ml}$ were $26 \%$ and $43 \%$ higher than those of the control cells (Table 2).

Effect of geraniin on intracellular killing activity of yeasts within macrophages

The intracellular killing activity of living yeasts was determined at $24 \mathrm{hr}$ after addition of geraniin. Viable yeasts within the macro- 
Table 1. Effect of geraniin on phagocytosis of living yeasts

\begin{tabular}{|c|c|c|c|c|c|c|}
\hline \multicolumn{2}{|c|}{ Treatment $^{a)}$} & \multicolumn{5}{|c|}{ Phagocytosis of yeasts (yeast cells/macrophage) ${ }^{b /}$} \\
\hline & $(\mu \mathrm{g} / \mathrm{ml})$ & 1 & 4 & 8 & 24 & $48 \quad(\mathrm{hr})$ \\
\hline Control & & $5.8 \pm 0.2$ & $6.0 \pm 0.3$ & $6.3 \pm 0.2$ & $6.2 \pm 0.2$ & $4.3 \pm 0.2$ \\
\hline \multirow[t]{4}{*}{ Geraniin } & 2 & $5.7 \pm 0.2$ & $6.1 \pm(0.2$ & $6.6 \pm 0.2$ & $7.0 \pm 0.2^{(\mathrm{)})}$ & $5.5 \pm 0.2^{(\mathrm{d})}$ \\
\hline & 5 & $6.0 \pm 0.2$ & $6.4 \pm 0.2$ & $7.7 \pm 0.3^{(j)}$ & $8.1 \pm 0.2^{\mathrm{e})}$ & $5.4 \pm 0.2^{\mathrm{d})}$ \\
\hline & 10 & $6.3 \pm 0.2$ & $6.3 \pm 0.2$ & $7.5 \pm 0.2^{\mathrm{d})}$ & $8.6 \pm 0.3^{()}$ & $5.9 \pm 0.2^{\mathrm{e})}$ \\
\hline & 20 & $6.2 \pm 0.2$ & $7.5 \pm 0.3^{\mathrm{d})}$ & $7.3 \pm 0.2^{\mathrm{d})}$ & $7.8+0.3^{\mathrm{d})}$ & $5.7 \pm 0.2^{\mathrm{d})}$ \\
\hline
\end{tabular}

${ }^{\text {a) }}$ The macrophages were incubated with $2 \%$ FCS-MEM medium containing various concentrations of geraniin $24 \mathrm{hr}$ after the cells were plated on culture dishes. 'The phagocytosis assay was performed at $1,4,8,24$ and $48 \mathrm{hr}$ after addition of geraniin to the cells. ${ }^{\text {()) } \mathrm{P}<0.05 .{ }^{\text {d) }} \mathrm{P}<}$ $0.01 .{ }^{*} \mathrm{P}<0.001$.

Table 2. Effect of geraniin on acid phosphatase activity in the lysates of cultured macrophages

\begin{tabular}{|c|c|c|c|c|c|c|}
\hline \multicolumn{3}{|c|}{ Treatment ${ }^{a)}$} & \multicolumn{3}{|c|}{ Acid phosphatase activity ( $\mathrm{mU} / \mathrm{mg}$ protein) ${ }^{\mathrm{bl}}$} & \multirow[b]{2}{*}{48 (hr) } \\
\hline & $(\mu \mathrm{g} / \mathrm{ml})$ & 1 & 4 & 8 & 24 & \\
\hline Control & & $123.3 \pm 8.6$ & $119.2 \pm 1.9$ & $146.8 \pm 10.9$ & $138.7 \pm 0.7$ & $66.0 \pm 2.9$ \\
\hline \multirow[t]{4}{*}{ Geraniin } & 2 & $119.6 \pm 1.8$ & $139.6 \pm 1.3$ & $158.9 \pm 11.4$ & $158.5 \pm 2.5^{\mathrm{e})}$ & $88.4 \pm 1.0^{\mathrm{c})}$ \\
\hline & 5 & $128.7 \pm 9.5$ & $132.3 \pm 5.3$ & $161.4 \pm 8.8$ & $155.2 \pm 5.1^{\circ)}$ & $91.1 \pm 4.4^{d)}$ \\
\hline & 10 & $131.6 \pm 1.6$ & $134.1 \pm 9.3$ & $145.0 \pm 1.6$ & $174.3 \pm 1.0^{\mathrm{e})}$ & $107.3 \pm 7.0^{\mathrm{t})}$ \\
\hline & 20 & $124.7 \pm 1.2$ & $122.5 \pm 2.6$ & $172.9 \pm 7.1$ & $198.0 \pm 6.2^{\mathrm{e})}$ & $128.7 \pm 3.8^{(2)}$ \\
\hline
\end{tabular}

a) The macrophages were incubated with $2 \%$ FCS-MEM medium containing various concentrations of geraniin $24 \mathrm{hr}$ after the cells were plated on culture dishes. ${ }^{\text {b) }}$ The enzyme activity was determined at $1,4,8,24$ and $48 \mathrm{hr}$ after additon of geraniin to the cells. ${ }^{\prime)} \mathrm{P}<0.05$. ${ }^{3)} \mathrm{P}<$ 0.01 . ${ }^{\prime \prime} \mathrm{P}<0.001$.

phage culture gradually declined with the time of incubation. The killing activity of yeasts by geraniin-treated macrophages was at the same level as that by control cells after incubation of the cells for an additional $165 \mathrm{~min}$ or 345 min (Table 3 ).

\section{Transmission electron microscopy}

Transmission electron microscopy showed that the control macrophages had a large number of small vacuoles localized mainly at the periphery of the cells and some dense granules in the cytoplasm. The cells treated with geraniin $(10 \mu \mathrm{g} / \mathrm{ml})$ for $24 \mathrm{hr}$ showed enlarged mitochondria. The cells treated with geraniin $(20 \mu \mathrm{g} / \mathrm{ml}$ ) for $24 \mathrm{hr}$ showed remarkably large mitochondria, more coated pits and prominent lysosomal granules within the enlarged cells, compared to the control cells (Fig. 3). In addition, quantitative examinations using an electronic planimeter showed that the mean area of the mitochondria within geraniin-treated macrophages was $71 \%$ larger than that within the control cells (Table 4).

\section{Labelling with ruthenium red staining}

An electron-dense surface coat was seen in the control macrophages based upon the negative surface charge of the cells. In the cells treated with geraniin $(20 \mu \mathrm{g} / \mathrm{ml})$ for $24 \mathrm{hr}$, the surface layer positive to ruthenium red was found to be significantly thicker than in the 
Table 3. Effect of geraniin on intracellular killing activity of yeasts by macrophages

\begin{tabular}{|c|c|c|c|c|}
\hline \multirow{2}{*}{\multicolumn{2}{|c|}{$\begin{array}{l}\text { Treatment }^{\mathrm{a})} \\
(\mu \mathrm{g} / \mathrm{ml})\end{array}$}} & \multicolumn{3}{|c|}{ Percentage of ingested yeasts after $15 \mathrm{~min}$ incubation } \\
\hline & & 3 & 6 & $(\mathrm{hr})^{\mathrm{b})}$ \\
\hline \multirow{3}{*}{$\begin{array}{l}\text { Control } \\
\text { Geraniin }\end{array}$} & & $36 \pm 4$ & $23 \pm$ & \\
\hline & 10 & $39 \pm 5$ & $25 \pm$ & \\
\hline & 20 & $38 \pm 2$ & $21 \pm$ & \\
\hline
\end{tabular}

\footnotetext{
${ }^{a)}$ The macrophages were further incubated with fresh $2 \%$ FCS-MEM medium containing various concentrations of geraniin $24 \mathrm{hr}$ after the cells were plated on culture dishes. ${ }^{\text {by }}$ After incubating the control and geranijn-treated macrophages for a further 165 or $345 \mathrm{~min}$, the cells were incubated with living yeasts for $15 \mathrm{~min}$ and then the killing activities determined.
}

Table 4. Effect of geraniin on area of mitochondria and the thickness of ruthenium red-positive layer of macrophages

\begin{tabular}{lcc}
\hline $\begin{array}{c}\text { Treatment } \\
(\mu \mathrm{g} / \mathrm{ml})\end{array}$ & $\begin{array}{c}\text { The mean arca } \\
\text { of mitochondria }\left(\mu \mathrm{m}^{2}\right)\end{array}$ & $\begin{array}{l}\text { The thickness of ruthenium } \\
\text { red-positive layer }(\mathrm{nm})^{\mathrm{b})}\end{array}$ \\
\cline { 2 - 3 } Control & $0.97 \pm 0.09$ & $28.5 \pm 2.7$ \\
Geraniin 20 & $1.67 \pm 0.14^{(2)}$ & $42.6 \pm 4.2^{\mathrm{c})}$ \\
\hline
\end{tabular}

a) The macrophages were incubated with $2 \%$ FCS-MEM medium containing geraniin 24 br after the cells were plated on culture dishes. ${ }^{\text {b) }}$ The analysis of morphometric parameters was performed on electron micrographs of macrophages fixed $24 \mathrm{hr}$ after the addition of geraniin. ${ }^{\mathrm{c}} \mathrm{P}<0.01$.

control cells (Fig. 4). In addition, quantitative examination using a micrometer showed that the mean thickness of the ruthenium red-positive layer on the membrane surface of geraniin-treated cells was $50 \%$ thicker, compared to that of the control cells (Table 4).

\section{DISCUSSION}

Geraniin remarkably increased the intracellular acid phosphatase activity of macrophages $24 \mathrm{hr}$ after the beginning of geraniin treatment. Acid phosphatase is mainly located in the lysosomal granules $(10,11)$. The lysosomal granules in the cytoplasm of geraniintreated macrophages were conspicuous $24 \mathrm{hr}$ after geraniin treatment by electron microscopy. In addition, geraniin-treated cells appeared to show more coated pits along the surface membrane. Coated pits may be involved in the fluid-phase pinocytosis and the membrane recycling (12). Unlike phagocytosis, pinocytosis is ongoing and constitutive and not generally susceptible to stimulation. Pinocytosis can internalize solutes either in the fluid phase or by adsorption of the substrate to the cell membrane (13). So, there is a possibility that the conspicuous lysosomal granules and increased number of coated pits, which could be seen within geraniin-treated macrophages, might be caused by the activated pinocytic process comprising internalization of soluble small vesicles including geraniin, followed by invagination of the surface membrane of macrophages.

Macrophages play a major role in host re- 

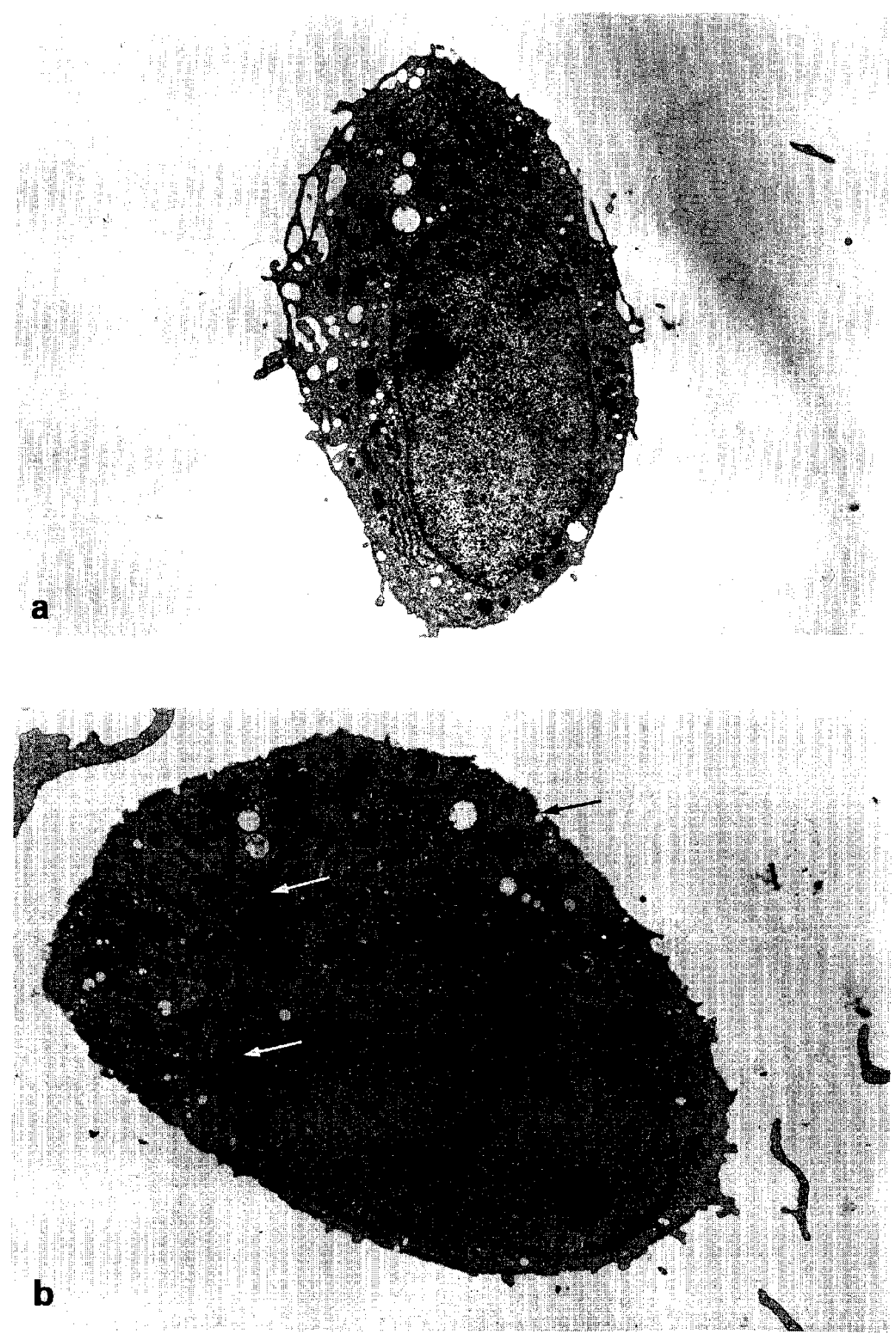

Fig. 3. Transmission clectron micrographs of cultured macrophages $(\times 12,000)$ a): Control cells possessed a large number of small vacuoles localized in the periphery of the cells. b): The cells treated with geraniin (20 $\mu \mathrm{g} / \mathrm{ml}$ ) for $24 \mathrm{hr}$ showed large mitochondria (white arrows) and more coated pits (black arrow) within the cells. 

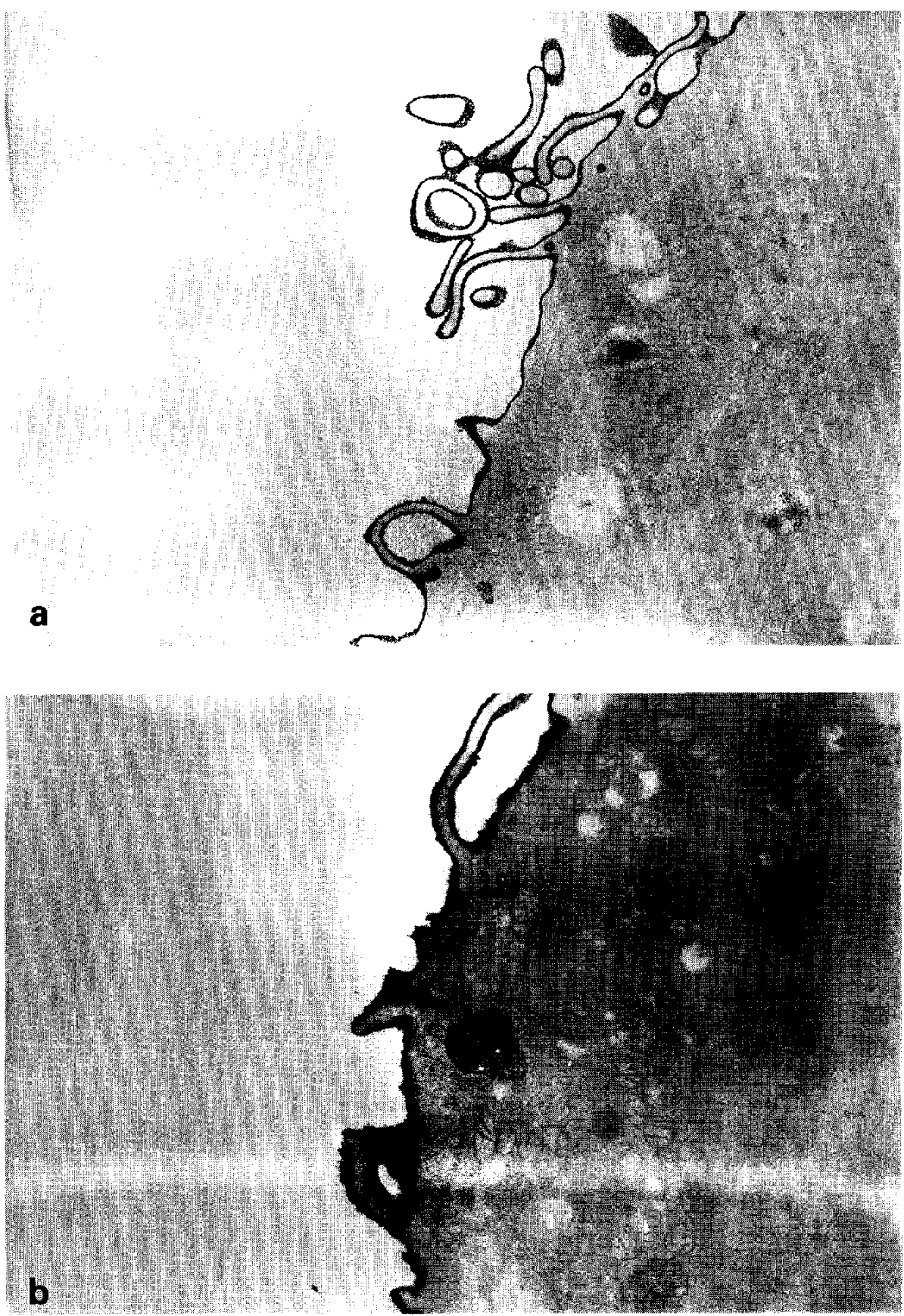

Fig. 4. Electron micrographs of macrophages stained by ruthenium red. $(\times 40,000)$ a): Contro] cells possessed the electron dense layer on the cell surface b): In the cells treated with geraniin $(20 \mu \mathrm{g} / \mathrm{ml}) \mathrm{for} 24 \mathrm{hr}$, the surface layer positive to ruthenium red was found to be significantly thicker than that in the control cells. 
sistance by ingesting and killing microorganisms. Geraniin had no effect on the intracellular killing activity of living yeasts after ingestion. The number of yeasts killed by geraniintreated macrophages might seem to be actually much more than that by the control cells, because the geraniin-treated macrophages ingested much more yeasts than control cells, even if the percent of yeasts killed intracellularly in geraniin-treated cells was the almost same as that in control cells. It is unclear whether the significant increase in acid phosphatase activity in geraniin-treated cells really affected the killing activity of yeasts and was caused by the alteration of the lysosomal mechanism. Furthermore, we must examine the activation mechanism of lysosomal enzyme activity to clarify whether the activation was caused by simple adsorption of geraniin to the surface membrane of macrophages or by delivery of geraniin to the lysosomes by fluid-phase pinocytosis.

Staining with ruthenium red provides a strong contrast of the cell surface and the invaginating tubules beneath it against the cytoplasm (14). The ruthenium red staining method is generally believed to allow detection of minute amounts of sulfate and carboxyl groups of acidic polysaccharides. As observed by electron microscopy, geraniin treatment scemed to induce remarkably thick sections on the ruthenium red-positive cell surface of macrophages, compared to control cells. We suggested that these thick layers were caused by geraniin binding to the some glycoproteins of the cell surface.

We have reported that geraniin treatment to mouse resident peritoneal macrophages in culture induces phagocytosis of yeasts in a dosedependent manner. The significant enhancement of phagocytosis was recognized $24 \mathrm{hr}$ after the beginning of geraniin treatment. The significant increases in both phagocytosis and cnzyme activity were exhibited $24 \mathrm{hr}$ after geraniin treatment. Although they are not directly related to each other, modification of the cell surface of macrophages by geraniin participated in not only increased the attach- ment and phagocytic process of yeasts, but also affected the transmembrane communication and coordinated cytoplasmic control. It is apparent that the plasma membrane is not an autonomous cell organelle. It is coupled to various cytoplasmic structures and other cell organelles (15). The morphological changes including changes in some ultrastructural features are accompanied by important changes in the physiology and function of macrophages $(16,17)$. We had already obtained the results that geraniin enhanced induced spreading, redistribution of cytoplasmic actin and extension of microtubules into the peripheral cytoplasm of cultured macrophages in vitro. The results suggested that the highly induced spreading activity in macrophages caused by geraniin appeared to be closely accompanied by stabilization of the microfilaments and microtubule network by geraniin binding to contractile proteins related to the cytoskeleton or membraneassociated proteins within the lipid bilayer. Taking this into consideration, we concluded that development of mitochondria, increase in phagocytosis of ycasts and enhancement of intracellular acid phosphatase activity in geraniin-treated macrophages were also induced by surface modification of macrophages by binding geraniin and were closely related to the increase in induced spreading and a highly organized cytoskeleton of macrophages caused by geraniin. We must further investigate what kind of cellular process such as cell division. development, differentiation towards death is concerned with functional modification and alteration of the surface membrane of macrophages by geraniin.

\section{REFERENCES}

1 Kimura, Y., Okuda, H., Okuda, T., Hatano, T.. Agata, I. and Arichi. S.: Studies on the activities of tannins and related compounds from medicinal plants and drugs. VI. Inhibitory effects of caffeoylquinic acids on histamine release from rat peritoneal mast cells. Chem. Pharm. Bull. (Tokyo) 33, $690-696$ ( 1985$)$

2 Rohrbach, M.S., Rolstad, R.A. and Russell, J.A.: Comparison of the tannin-mediated secretion of 
granule and lysosome components from human platelets. Thromb. Res. 48, $117-123$ (1987)

3 Hempel, S.L.. Wheatley, C.L. and Rohrbach, M.S.: Protein phosphorylation during tannin-mediated activation of human platelets. J. Lab. Clin. Med. 111. $299-306$ (1988)

4 Vuk-Pavlovic, Z., Russell, J.A. and Rohrbach, M.S.: Cotton bract tannin: A novel human T-lymphocyte mitogen and a possible causative agent of byssinosis. Int. Arch. Allergy Appl. Immunol. 87. $14-18$ (1988)

5 Miyamoto, K., Kishi, N., Murayama, T., Furukawa, T. and Koshiura, R.: Induction of cytotoxicity of peritoneal exudate cells by agrimoniin, a novel immunomodulatory tannin of Agrimonia pilosa Ledeb. Cancer Immunol. Immunother. 27, 59-62 (1988)

6 Dawra, R.K., Makkar, H.P.S. and Singh, B.: Protein-binding capacity of microquantities of tannins. Anal. Biochem. 170,50-53 (1988)

7 Rohrbach, M.S., Kreofsky. T., Rolstad, R.A. and Russell, J.A.: Tannin mediated sccretion of a neutrophil chemotactic factor from alveolar macrophages. Potential contribution of the acute pulmonary inflammatory reaction associated with byssinosis. Am. Rev. Respir. Dis. 139, $39-45$ (1989)

8 Hempel, S.L. and Rohrbach, M.S.: Tannin mediated alveolar macrophage protein phosphorylation. Mol. Cell Biochem. 86, 163-170 (1989)

9 Grasso, R.J. and Guay, R.C.. Jr.: A feasibility study to determine if microbicidal activity can be mcasured in dexamethasone-treated macrophage cultures. Adv. Exp. Med. Biol. 166, 279-283 (1983)

10 Nichols, B.A.: Normal rabbit alveolar macrophages II. Their primary and secondary lysosomes as revealed by electron microscopy and cytochemistry. J. Exp. Med. 144, 920-932 (1976)

11 North R.J.: The concept of the activated macrophage. J. Immunol. 121, $806-809$ (1978)

12 Stcinman, R.M., Brodic, S.E. and Cohn, Z.A.: Membrane flow during pinocytosis. A stereologic analysis. J. Cell Biol. 68, $665-687$ (1976)

13 Pratten, M.K. and Lloyd, J.B.: Pinocytosis and phagocytosis: the effect of size of a particulate substrate on its mode of capture by rat peritoneal macrophages cultured in vitro. Biochim. Biophys. Acta 881, 307-313 (1986)

14 Takata, K., Arii, T., Yamagishi, S. and Hirano, $H$.: Use of colloidal gold and ruthenium red in stereo high-voltage electron microscopic study of ConA-binding sites in mouse macrophages. Histochemistry 81, $441-444$ (1984)

15 Nicolson, G.L.: Transmembrane control of the receptors on normal and tumor cells. Biochim. Biophys. Acta 457, 57-108 (1976)

16 Cohn, Z.A. and Benson, B.: The differentiation of mononuclear phagocytes: Morphology, cytochemistry, and biochemistry. J. Exp. Med. 121, 153$170(1965)$

17 Cohn, Z.A., Fedorko, M.F. and Hirsch, J.G.: The in vitro differentiation of mononuclear phagocytes. $\mathrm{V}$. The formation of macrophage lysosomes. J. Exp. Med. 123, $757-766$ (1969) 